\title{
FAKTOR-FAKTOR YANG MEMPENGARUHI TERJADINYA PERDARAHAN PASCA PERSALINAN DI RUMAH SAKIT UMUM DAERAH KOTA PRABUMULIH
}

\author{
FACTORS AFFECTING THE LOSS OF POST-LABORING LABOR IN THE REGIONAL \\ GENERAL HOSPITAL INPRABUMULIH \\ Gustika Anggriani \\ Akademi Kebidanan Rangga Husada Prabumulih, Sumatera Selatan \\ email: gustika.ranggahusada@gmail.com
}

\begin{abstract}
ABSTRAK
Perdarahan pasca persalinan yaitu adalah perdarahan atau hilangnya darah sebanyak lebih dari $500 \mathrm{ml}$ yang terjadi setelah anak lahir baik sebelum, selama, atau sesudah kelahiran plasenta.Tujuanpenelitianadalahfaktorfaktor yang mempengaruhi terjadinya perdarahan pasca persalinan di Rumah Sakit Umum Daerah Tahun 2019. Metode penelitian bersifat analitik, dengan mengunakan pendekatan Cross Sectional.Populasi penelitian ini adalah seluruh ibu bersalindiruang kebidananRumah Sakit Umum DaerahKota Prabumulih dari tanggal 1 Januari sampai dengan 31 Desember 2019 yaitu sebanyak 1712 orang. Sampel penelitian adalah sebagian dari populasi yaitu 324 orang.Instrumen penelitian berupa kuesioner.Kesimpulan ada hubungan yang bermakna antara partus lama dengan kejadian perdarahan pasca persalinan dengannilai Pvalue $0,000<\alpha 0,05$, ada hubungan yang bermakna antara makrosomia dengan kejadian perdarahan pasca persalinan dengannilai Pvalue $0,000<0,05$ danada hubungan yang bermakna antara anemia dengan kejadian perdarahan pasca persalinan dengannilai Pvalue $0,000<0,05$
\end{abstract}

Kata Kunci : Perdarahan pasca persalinan, partus lama, makrosomia, anemia

\begin{abstract}
Postpartum hemorrhage that is more than $500 \mathrm{ml}$ of bleeding or blood loss that occurs after the child is born either before, during, or after the birth of the placenta.The research objectives are the factors that influence the occurrence of postpartum bleeding in the Regional General Hospital in 2019. The research method is analytic, using the Cross Sectional approach. The population of this study was all of the maternity mothers in the midwifery room of the Prabumulih City Regional General Hospital from January 1 to December 31, 2019, totaling 1712 people. The research sample is part of the population of 324 people. The research instrument was in the form of a questionnaire. Conclusion there is a significant relationship between old parturition with the incidence of postpartum bleeding with a $P$ value of $0.000<\alpha 0.05$, there is a significant relationship between macrosomia with the incidence of postpartumbleeding with a $P$ value of 0,000<0.05 and there is a significant relationship between anemia and the incidence of postpartum hemorrhage with a $P$ value of $0,000<0.05$
\end{abstract}

Keywords: Postpartum bleeding, old parturition, macrosomia, anemia 


\section{PENDAHULUAN}

Perdarahan pasca persalinan adalah perdarahan atau hilangnya darah sebanyak lebih dari $500 \mathrm{ml}$ yang terjadi setelah anak lahir baik sebelum, selama, atau sesudah kelahiran plasenta. Kondisi dalam persalinan menyebabkan kesulitan untuk menentukan jumlah perdarahan yang terjadi karena tercampurdengan air ketuban dan serapan pakaian atau kain alas tidur ${ }^{1}$.

Perdarahan pasca persalinan dapat terjadi pada kelahiran dengan makrosomia, hal ini disebabkan karena besarnya janin menyebabkan terjadi regangan pada uterus mulai sejak kehamilan sampai persalinan. Sehingga, menyebabkan kelelahan miometrium dan terganggunya kontraksi uterus setelah melahirkan dan pada persalinan normal bayi dengan makrosomia bisa menyebabkan ruptur perineum yang dapat meyebabkan terjadinya perdarahan pascapersalinan ${ }^{l}$.

Data World Health Organization (2018) menunjukan bahwa 25.000 dari kematian maternal disebabkan oleh perdarahan pasca persalinan dan diperkirakan 100.000 kematian maternal setiap tahunnya.Di berbagai Negara paling sedikit seperempat dari seluruh kematian ibu disebabkan oleh perdarahan, proposinya berkisar antara kurang dari $10-60 \%{ }^{2}$.

Sustainable Development Goal (SDG's) merupakan sebuah dokumen yang akan menjadi acuan dalam kerangka pembangunan dan perundingan negaranegara didunia, salah satu indikator pencapaian SDG's adalah pada tahun 2030 terjadi penurunan rasio kematian ibu yang kurang dari 70 per 100.000 kelahiranhidup dan pada tahun 2030 mengakhiri dan mencegah kematian bayi dan balita ${ }^{3}$.

Di Indonesia diperkirakan ada 14 juta kasus perdarahan dalam kehamilan. Setiap tahunnya paling sedikit 128.000 perempuan mengalami perdarahan sampai meninggal.Perdarahan pasca persalinan terutama perdarahan pasca persalinan primer merupakan perdarahan yang paling banyak menyebabkan kematian ibu. Perdarahan pasca persalinan primer yaitu perdarahan pasca persalinan yang terjadi dalam 24 jam pertama kelahiran ${ }^{4}$.

Faktor penyebab perdarahan pasca persalinan antara lain : ibu hamil tidak pernah memeriksakan kehamilannya, memeriksakan kehamilan tetapi tidak teratur, atonia uteri retensio plasenta, ruptur uteri, inversio uteri, trauma jalan lahir dan gangguan sistem pembekuan darah, faktor predisposisi yang harus dipertimbangkan adalah usia ibu, riwayat perdarahan pasca persalinan sebelumnya, grandemultipara, perdarahan antepartum, dan partus lama ${ }^{5}$.

Menurut hasil penelitian Psiari Kusuma (2017) tentang faktor- faktor yang mempengaruhi terjadinya perdarahan pasca persalinan, dari 71 responden terdapat hasil Uji statistic Chi-Square didapatkan $p$-value $=0,000$ untuk partuslama artinya ada hubungan bermakna antara partus lama dengan kejadian perdarahan pasca persalinan ${ }^{4}$.

Makrosomia merupaka satu factor risiko terjadinya perdarahan postpartum. Makrosomia didefinisikan sebagai berat lahir bayi >4000 gram. insiden makrosomia telah meningkat dinegara maju, meskipun makrosomia mungkin kurang umum di Negara-negara berkembang. Pada umumnya, berat lahir bayi $>4000$ gram terjadi pada $10 \%$ dari seluruh persalinan sedangkan berat lahir bayi $\geq 4500$ gram terjadi $1 \%$ dari seluruh persalinan. Survey kematian perinatal yang dilakukan bagian kedokteran obstetric dan ginecology spanyol menunjukkan bahwa insiden bayi dengan berat lahir $>4000$ 
gram adalah $6,7 \%$ fan $0,8 \%$ bayi dengan berat lahir $>4500$ gram $^{6}$.

Partus lama dapat menimbulkan efek terhadap ibu maupun janin.Pada partus lama terdapat kenaikan insidensi atonia uteri, laserasi, perdarahan, infeksi, kelelahan ibu dan syok. Partus lama dapat menyebabkan terjadinya inersia uteri karena kelelahan pada otot - otot uterus sehingga rahim berkontraksi lemah setelah bayi lahir dan dapat menyebabkan terjadinya perdarahan pasca persalinan ${ }^{4}$.

Wanita yang mengalami anemia dalam persalinan dengan kadar hemoglobin $<11 \mathrm{gr} / \mathrm{dl}$ akan dengan cepat terganggu kondisinya bila terjadi kehilangan darah meskipun hanya sedikit. Anemia dihubungkan dengan kelemahan yang dapat dianggap sebagai penyebab langsung perdarahan pasca persalinan ${ }^{7}$.

Berdasarkan data yang diperoleh dari Rumah Sakit Umum Daerah Kota Prabumulih, diketahui bahwa pada tahun 2017 terdapat 127 orang $(9,17 \%)$ dengan pendarahan pasca persalinan dari $1385 \mathrm{ibu}$ bersalin, tahun 2018 terdapat 150 orang $(9,24 \%)$ dengan pendarahan pasca persalinan dari 1622 ibu bersalin, tahun 2019 terdapat 168 orang $(9,81 \%)$ dengan pendarahan pasca persalinan dari $1712 \mathrm{ibu}$ bersalin ${ }^{8}$.

Berdasarkan data di atas maka penulis tertarik untuk melakukan penelitian dengan judul "Faktor-faktor yang mempengaruhi terjadinya perdarahan pasca persalinan di Rumah Sakit Umum Daerah kota prabumulih".

\section{METODE PENELITIAN}

Penelitian ini menggunakan studyanalitik dengan pendekatanCross Sectional Study ialah suatu penelitian untuk mempelajari dinamika korelasi antara faktor-faktor resiko dengan efek dengan cara pendekatan observasi / pengumpulan data sekaligus pada suatu saat ${ }^{9}$.

Dimana variabel independen pada penelitian ini yaitu partus lama, Makrosomia, dan anemia sedangkan variabel dependen yaitu perdarahan pasca persalinan dikumpulkan dalam waktu yang bersamaan.

Populasi kasus dalam penelitian ini adalah seluruh ibu bersalin yang dicatat dalam catatan medic di Rumah Sakit Umum Daerah Kota Prabumulih dari 1 Januari sampai dengan 31 Desember 2020 yaitu sebanyak 1712 responden.

Teknik pengambilan sampel yang digunakan dalam penelitian ini adalah simple random sampling, dimana setiap sampel dari sejumlah populasi, Hal ini dimaksudkan agar setiap individu pada populasi kasus maupun populasi kontrol mendapatkan peluang yang sama sebagai sampel penelitian, sehingga hasil yang didapatkan dapat mewakili keseluruhan populasi.

\section{HASIL PENELITIAN}

\section{Karakteristik Responden}

Berdasarkan hasil penelitian didapatkan data karakteristik responden dari 324 ibu bersalin di wilayah kerja rumah sakit umum daerah kota prabumulih tahun 2019 yang dibagi berdasarkan partus lama, makrosomia dan anemia dengan kejadian perdarahn pasca persalinan. 
Tabel 1. Distribusi Karakteristik Perdarahan Pasca Persalinan, Partus Lama, Makrosomia dan Anemia

\begin{tabular}{clcc}
\hline No & \multicolumn{1}{c}{ Karakteristik } & Jumlah & Presentase (\%) \\
\hline 1 & Perdarahan Pasca Persalinan & & \\
& a. Ya & 87 & 26,9 \\
& b. Tidak & 237 & 73,1 \\
\hline 2 & Partus Lama & & \\
& a. Ya & 14 & 4,3 \\
& b. Tidak & 310 & 95,7 \\
\hline $3 \quad$ Makrosomia & & \\
& a. 1 3 Paritas & 27 & 8,3 \\
& b. 2 dan 3 Paritas & 297 & 91,7 \\
\hline 4 & Anemia & & \\
& Ya & 19 & 5,9 \\
& Tidak & 305 & 94,1 \\
\hline
\end{tabular}

Tabel di atas menunjukkan bahwa sebagian ibu yang mengalami perdarahan pasca perdarahan sebanyak $87(26,9 \%)$ dan yang tidak mengalami perdarahan pasca perdarahan sebanyak $237(73,1 \%)$. Dari karakteristik partus lama menunjukkan dari 310 responden $(95,7 \%)$ yang tidak didiagnosa partus lama lebih banyak dibandingkan responden yang didiagnosa partus lama yaitu 14 responden $(4,3 \%)$. Kemudian dari karateristik makrosomia terdapat 297 responden $(91,7 \%)$ yang memiliki janin yang tidak mengalami makrosomia lebih banyak dibanding dengan responden yang memiliki janin yang mengalami makrosomia yaitu 27 responden $(8,3 \%)$. Sedangkan dari karakteristik anemia terdapat 305 responden $(94,1 \%)$ yang tidak mengalami anemia lebih banyak dibanding dengan responden yang mengalami anemia yaitu 19 responden $(5,9 \%)$.

Hasil Analisis Bivariat

Tabel 2. Hubungan Antara Partus Lama dengan Kejadian Perdarahan Pasca Persalinan

\begin{tabular}{|c|c|c|c|c|c|c|c|}
\hline \multirow{3}{*}{ Partus lama } & \multicolumn{6}{|c|}{ Kejadian Perdarahan Pasca Persalinan } & \multirow{3}{*}{ Pvalue } \\
\hline & \multicolumn{2}{|c|}{ Ya } & \multicolumn{2}{|c|}{ Tidak } & \multicolumn{2}{|c|}{ Jumlah } & \\
\hline & $\mathbf{n}$ & $\%$ & $\mathbf{n}$ & $\%$ & $\mathbf{N}$ & $\%$ & \\
\hline Ya & 11 & 3,4 & 3 & 9 & 14 & 4,3 & \\
\hline Tidak & 76 & 23,5 & 234 & 72,2 & 310 & 95,7 & 0,000 \\
\hline Jumlah & 87 & 26,9 & 237 & 73,1 & 324 & 100 & \\
\hline
\end{tabular}

Dari tabel di atas dapat dilihat bahwa dari 324 responden terdapat 14 responden yang mengalami partus lama, dimana 11 responden $(3,4 \%)$ didiagnosa perdarahan pasca persalinan dan 3 responden $(9 \%)$ yang tidak didiagnosa perdarahan pasca persalinan sedangkan dari 310 responden yang tidak mengalami partus lama terdapat 76 responden $(23,5 \%)$ didiagnosa perdarahan pasca persalinan dan 234 responden $(72,2 \%)$ tidak didiagnosa perdarahan pasca persalinan. 
p-ISSN: 2503-1392

e-ISSN: 2620-5424

Tabel 3. Hubungan Antara Makrosomia dengan Kejadian Perdarahan Pasca Persalinan

\begin{tabular}{|c|c|c|c|c|c|c|c|}
\hline \multirow{3}{*}{ Makrosomia } & \multicolumn{6}{|c|}{ Kejadian Perdarahan Pasca Persalinan } & \multirow{3}{*}{ Pvalue } \\
\hline & \multicolumn{2}{|c|}{ Ya } & \multicolumn{2}{|c|}{ Tidak } & \multicolumn{2}{|c|}{ Jumlah } & \\
\hline & $\mathbf{n}$ & $\%$ & $\mathbf{n}$ & $\%$ & $\mathbf{N}$ & $\%$ & \\
\hline $\mathrm{Ya}$ & 19 & 5,9 & 8 & 2,4 & 27 & 8,3 & \\
\hline Tidak & 68 & 21 & 229 & 70,7 & 297 & 91,7 & 0,000 \\
\hline Jumlah & 87 & 26,9 & 237 & $\mathbf{7 3 , 1}$ & 324 & 100 & \\
\hline
\end{tabular}

Dari tabel di atas dapat dilihat bahwa dari 324 responden terdapat 27 responden yang memiliki janin dengan makrosomia, dimana 19 responden $(5,9 \%)$ yang didiagnosa perdarahan pasca persalinan dan 8 responden $(2,4 \%)$ tidak didiagnosa perdarahan pasca persalinan sedangkan dari 297 responden yang tidak memiliki janin dengan makrosomia terdapat 68 responden $(21 \%)$ yang didiagnosa perdarahan pasca persalinan dan 229 responden $(70,7 \%)$ yang tidak didiagnosa perdarahan pasca persalinan.

Tabel 4. Hubungan Antara Anemia dengan Kejadian Perdarahan Pasca Persalinan

\begin{tabular}{|c|c|c|c|c|c|c|c|}
\hline \multirow{3}{*}{ Anemia } & \multicolumn{6}{|c|}{ Kejadian perdarahan pasca persalinan } & \multirow{3}{*}{ Pvalue } \\
\hline & \multicolumn{2}{|c|}{ Ya } & \multicolumn{2}{|c|}{ Tidak } & \multicolumn{2}{|c|}{ Jumlah } & \\
\hline & $\mathbf{n}$ & $\%$ & $\mathbf{n}$ & $\%$ & $\mathbf{N}$ & $\%$ & \\
\hline Ya & 15 & 4,7 & 4 & 1,2 & 19 & 5,9 & \\
\hline Tidak & 72 & 22,2 & 233 & 71,9 & 305 & 94,1 & 0,000 \\
\hline Jumlah & 87 & 26,9 & 237 & 73,1 & 324 & 100 & \\
\hline
\end{tabular}

Dari tabel di atas dapat dilihat bahwa dari 324 responden terdapat 19 responden yang mengalami anemia, dimana 15 responden $(4,7 \%)$ yang didiagnosa perdarahan pasca persalinan dan 4 responden $(1,2 \%)$ tidak didiagnosa perdarahan pasca persalinan sedangkan dari 305 responden yang tidak mengalami anemia terdapat 72 responden $(22,2 \%)$ yang didiagnosa perdarahan pasca persalinan dan 233 responden $(71,9 \%)$ yang tidak didiagnosa perdarahan pasca persalinan.

\section{PEMBAHASAN}

Hubungan partus lama dengan kejadian perdarahan pasca persalinan

Berdasarkan dari hasil Uji statistic ChiSquare didapatkan $p$-value $=0,000$ artinya partus lama dengan kejadian perdarahan pasca persalinan ada hubungan yang bermakna, sehingga hipotesis yang menyatakan ada hubungan yang bermakna antara partus lama dengan kejadian perdarahan pasca persalinan terbukti secara statistik.

Hasil penelitian ini sejalan dengan hasil penelitian Psiari Kusuma (2017) tentang faktor-faktor yang mempengaruhi terjadinya perdarahan pasca persalinan, dari 71 responden terdapat hasil Uji statistic Chi-Square didapatkan $p$-value $=$ 0,000 dan 0,001 untuk partus lama dan riwayat seksio sesarea artinya ada hubungan bermakna antara partus lama dan riwayat seksio sesarea dengan kejadian perdarahan pasca persalinan ${ }^{4}$.

Partus lama adalah persalinan yang berlangsung lebih dari 24 jam pada primi dan lebih dari 18 jam pada multi. Partus lama baik fase aktif memanjang maupun 
kala II memanjang menimbulkan efek terhadap ibu maupun janin.Terdapat kenaikan terhadap insidensi atonia uteri, laserasi, perdarahan, infeksi, kelelahan ibu dan syok.

Partus lama dapat menyebabkan terjadinyainersia uteri karena kelelahan pada otot-otot uterus sehingga rahim berkontraksi lemah setelah bayi lahir dan dapat menyebabkan terjadinya perdarahan pasca persalinan ${ }^{4}$.

Penelitian oleh Dina, Seweng, dan Nyorong (2013) menyatakan bahwa partus lama merupakan faktor resiko perdarahan postpartum, dimana besar resikonya adalah 3,5 yang artinya ibu yang mengalami partus lama mempunyai resiko 3,5 kali lebih besar untuk mengalami perdarahan post partum dibandingkan ibu yang tidak mengalami partus lama ${ }^{10}$.

Hubungan makrosomia dengan kejadian perdarahan pasca persalinan

Berdasarkan dari hasil Uji statistic ChiSquaredidapatkan $p$-value $=0,000$ artinya antara makrosomia dengan kejadian perdarahan pasca persalinan ada hubungan yang bermakna, sehingga hipotesis yang menyatakan ada hubungan yang bermakna antara makrosomia dengan kejadian perdarahan pasca persalinanterbukti secara statistik.

Hasil penelitian ini sejalan dengan hasil penelitian Fitria (2015) tentang hubungan partus lama, riwayat perdarahan postpartum dan berat bayi lahir besar (makrosomia) dengan kejadian perdarahan postpartum di RSUD Kanjuruhan Kepanjen Malang Tahun 2015, dari 71 responden terdapat hasil Uji statistic ChiSquare didapatkan $p$-value $=0,001$ untuk makrosomia artinya ada hubungan bermakna antara makrosomia dengan kejadian perdarahan pasca persalinan ${ }^{11}$.
Berat bayi lahir yang lebih dari normal atau yang dalam penelitian ini disebut makrosomia dapat menyebabkan perdarahan postpartum karena uterus meregang berlebihan dan mengakibatkan lemahnya kontraksi sehingga dapat terjadi perdarahan postpartum.Kondisi ini karena uterus mengalami overdistensisehingga mengalami hipotoni atau atonia uteri setelah persalinan. Adapun beberapa keadaan overdistensi uterus yang juga dapat menyebabkan atonia uteri yaitu kehamilan ganda dan hidramnion ${ }^{11}$.

Hubungan anemia dengan kejadian perdarahan pasca persalinan

Berdasarkan dari hasil Uji statistic ChiSquaredidapatkan $p$-value $=0,000$ artinya antara anemia dengan kejadian perdarahan pasca persalinan ada hubungan yang bermakna, sehingga hipotesis yang menyatakan ada hubungan yang bermakna antara anemia dengan kejadian perdarahan pasca persalinan terbukti secara statistik.

Hasil penelitian ini sejalan dengan hasil penelitian yang dilakukan Yekti (2017) tentang faktor-faktor yang mempengaruhi kejadian perdarahan pasca persalinan di RSUD Panembahan Senopati Kabupaten Bantul, dengan 80 responden terdapat $50 \%$ responden mengalami perdarahan dan terdapat hasil Uji statistic Chi-Square didapatkan $p$-value $=0,016$ yang berarti bahwa ada hubungan yang bermakna antara anemia dengan kejadian perdarahan pasca persalinan ${ }^{7}$.

Anemia adalah suatu keadaan yang ditandai dengan penurunan nilai hemoglobin di bawah nilai normal, ibu hamil dikatakan anemia jika kadarhemoglobin kurang dari $11 \mathrm{~g} / \mathrm{dL}$. Kekurangan hemoglobin dalam darah dapat menyebabkan komplikasi lebih serius bagi ibu baik dalam kehamilan, persalinan, dan nifas ${ }^{12}$. 
Wanita yang mengalami anemia dalam persalinan dengan kadar hemoglobin $<11 \mathrm{gr} / \mathrm{dl}$ akan dengan cepat terganggu kondisinya bila terjadi kehilangan darah meskipun hanya sedikit. Anemia dihubungkan dengan kelemahan yang dapat dianggap sebagai penyebab langsung perdarahan postpartum ${ }^{7}$.

\section{KESIMPULAN}

Berdasarkan hasil penelitian dapat disimpulkan sebagai berkut :

Ada hubungan antara partus lama dengan kejadian perdarahan pasca persalinan di Rumah Sakit Umum Daerah kota Prabumulih dengan Chi-Square didapatkan $p$-value $=0,000 \leq \alpha(0,05)$.

Ada hubungan antara makrosomia dengan kejadian perdarahan pasca persalinan di Rumah Sakit Umum Daerah kota Prabumulihdengan Chi square didapatkan $p$ value $=0,000 \leq \alpha(0,05)$.

Ada hubungan antara anemia dengan kejadian perdarahan pasca persalinan di Rumah Sakit Umum Daerah kota Prabumulih dengan Chi square didapatkan $p$ value $=0,000 \leq \alpha(0,05)$.

\section{SARAN}

Kepada tenaga kesehatan di poliklinik kebidanan untuk dapat meningkatkan kualitas dan kuantitas pelayanan pemeriksaan kehamilan sehingga dapat mendeteksi kelainan pada ibu hamil sejak dini dan meningkatkan penyuluhan tentang tanda bahaya kehamilan agar angka kejadian perdarahan postpartum menurun.

Bagi masyarakat untuk dapat memahami tentang perdarahan postpartum, dan bagi masyarakat khususnya ibu hamil untuk dapat secara rutin memeriksakan kehamilannya sehingga kesehatan ibu dan janin dapat terjaga dengan baik.

\section{DAFTAR PUSTAKA}

1. Prawirohardjo, Sarwono. 2016. Pelayanan Kesehatan Maternal dan Neonatal. Edisi Pertama. Jakarta. YBP-SP.

2. World Health Organization (WHO). 2018. WHO, UNICEF, UNFPA, The WorldBank.Trends in maternal mortality: 1990 to 2013.

3. Ayulia. fardilasari. 2015. Sustainable Development Goal (SDG's). .(http://www.ayulia. blogspot. com diakses 10 Februari 2020).

4. Psiari Kusuma. 2017.faktor- faktor yang mempengaruhi terjadinya perdarahan pasca persalinan RSUD dr. A. Dadi Tjokrodipo Kota Bandar Lampung ((http://www.Psiari kusuma blogspot.com. di akses18 Februari 2020)

5. Mansjoer. 2015. Kapita Selekta Kedokteran. Edisi ketiga. Jakarta, Media Aesculapius.

6. Asim Kurjak chervenak frank A. 2006. Textbook of perinatal medicine $2^{\text {nd }}$ edition medicine informa healthcare UK Ltd.

7. Yekti. 2017. Faktor-faktor yang mempengaruhi kejadian perdarahan post partum di RSUD Panembahan Senopati Kabupaten Bantul( http://www.Yekti blogspot.com diakses 19 Februari 2020)

8. Tim penulis RSUD Prabumulih. 2019, Profil RSUD Kota Prabumulih

9. Notoatmodjo,S. 2010. Ilmu Kesehatan Masyarakat. Jakarta. Rineka Cipta

10. Dina. 2013. Hubungan partus lama dan anemia dengan kejadian perdarahan postpartum diRSUD Ambarawa (http://www.Dina blogspot.com diakses 19 Februari 2020).

11. Fitria. 2015. Hubungan partus lama, riwayat perdarahan postpartum dan berat bayi lahir besar dengan kejadian perdarahan postpartum di RSUD Kanjuruhan Kepanjen Malang 
p-ISSN: 2503-1392

e-ISSN: 2620-5424

Tahun 2013. (http://www.Fitria blogspot. com diakses 15 Februari 2020)

12. Manuaba, I, B, G. Bagus Gede. 2010. Ilmu Kebidanan, Penyakit Kandungan dan $K B$, Jakarta, ECG. 